\title{
Functional abdominal pain in childhood: Background studies and recent research trends
}

\author{
Rona L Levy MSW PhD MPH ${ }^{1}$, Miranda AL van Tilburg PhD ${ }^{2}$
}

RL Levy, MAL van Tilburg. Functional abdominal pain in childhood: Background studies and recent research trends. Pain Res Manage 2012;17(6):413-417.

The present review summarizes many of the major research trends investigated in the past five years regarding pediatric functional abdominal pain, and also summarizes the primary related findings from the authors' research program. Specific areas discussed based on work within the authors' group include familial illness patterns, genetics, traits, and mechanisms or processes related to abdominal pain. Topics covered from research published in the past five years include prevalence and cost, longitudinal follow-up, overlap with other disorders, etiology and mechanisms behind functional abdominal pain and treatment studies. It is hoped that findings from this work in abdominal pain will be interpreted as a framework for understanding the processes by which other pain phenomena and, more broadly, reactions to any physical state, can be developed and maintained in children. The present article concludes with recommendations for clinical practice and research.

Key Words: Parental influence; Pediatrics; Review

\section{La douleur abdominale fonctionnelle pendant l'enfance : des études préliminaires et les récentes tendances de la recherche}

Le présent revue contient un résumé de bon nombre des grandes tendances de la recherche explorées depuis cinq ans au sujet de la douleur abdominale fonctionnelle en pédiatrie, ainsi que les principaux résultats connexes du programme de recherche des auteurs. Les domaines abordés d'après les travaux au sein du groupe d'auteurs incluent les profils familiaux de maladie, la génétique, les caractéristiques et les mécanismes ou processus liés aux douleurs abdominales. Les sujets abordés dans les résultats de recherche publiés depuis cinq ans incluent la prévalence et les coûts, le suivi longitudinal, le chevauchement avec d'autres troubles, l'étiologie et les mécanismes de la douleur abdominale fonctionnelle ainsi que les études thérapeutiques. On espère que les résultats de ces travaux sur la douleur abdominale seront perçus comme un cadre pour comprendre les processus par lesquels les enfants peuvent acquérir et conserver d'autres phénomènes liés à la douleur et, plus largement, des réactions à un état physique. Le présent article se termine par des recommandations de pratique clinique et de recherche.

A publication by the Association of American Physicians Subcommittee and the North American Society for Pediatric Gastroenterology, Hepatology and Nutrition Committee on Chronic Abdominal Pain (1) explains that the term 'RAP' is a common abbreviation for recurrent abdominal pain, as defined by Apley and Naish (2). Under this definition, children were considered to have recurrent abdominal pain if they had experienced at least three bouts of pain severe enough to affect activities over a period of at least three months. The current preference is to use the term 'functional abdominal pain' (FAP), which is defined as abdominal pain that occurs in the absence of anatomical abnormality, inflammation or tissue damage (1). Therefore, the present article will use the more current, generic term of 'FAP'.

Another term that will be used in the present article that may be unfamiliar to some readers is 'illness behaviour'. The term 'disease' refers to pathophysiological changes in tissues, whereas 'illness behaviour' refers to the way individuals perceive and react to somatic sensations that may signify disease (3). Some fail to notice such sensations or refuse to let illness interrupt their normal routine, while others misinterpret normal somatic sensations as symptoms of disease and may seek medical treatment for minor complaints. Illness behaviour is a term used to describe this continuum, which ranges from denial of disease at one extreme to disability that is disproportionate to physical findings at the other extreme. Both ends of the illness behaviour continuum are of concern to health care providers. Denial may lead individuals to postpone diagnostic investigations or to not adhere to medical regimens. Preoccupation with illness, on the other hand, creates a costly burden on the health care system (4) and can have a significant impact on an individual's life. Most research in this area focuses on the high end of the illness behaviour continuum.

${ }^{1}$ School of Social Work, University of Washington, Seattle, Washington; ${ }^{2}$ Department of Gastroenterology and Hepatology, University of North Carolina, Chapel Hill, North Carolina, USA

Correspondence: Dr Rona L Levy, University of Washington, Mailstop 354900, Seattle, Washington 98105, USA.

Telephone 206-543-5917, fax 425-488-3616, e-mail rlevy@uw.edu 
Shulman et al (19) observed increased gastrointestinal permeability and gut inflammation in children with FAP and irritable bowel syndrome (IBS), while Saps et al (20) found significant increases in functional gastrointestinal disorders after bacterial infections in children. Schurman et al (21) found a relationship between mucosal inflammation and psychological functioning, and Saps et al (22) suggested that cow's milk allergy may be a risk factor.

Hypersensitivity in FAP: There is a large body of literature on hypersensitivity in FAP in the adult population; however, studies in children were lacking until recently. There has been some catch up in the past five years, with the main findings mimicking those observed in adults (23-25), specifically:

- Children with FAP exhibit increased visceral hypersensitivity compared with control children and those with organic disease.

- There is no evidence of somatic hypersensitivity in FAP.

- Visceral hypersensitivity may be a marker for functional gastrointestinal disorders in children, but sensitivity remains low.

- Initial results suggest there is general attentional bias in FAP and increased sensitivity persists in those who recover.

Blood pressure and heart rate: While there is some initial evidence of decreased baroreceptor sensitivity in children, further research is required due to various methodological limitations (26-28).

Stress/coping/psychological factors: Most recent studies add relatively little to the findings of previous work, with many showing that psychological distress is associated with pain and disability. Specifically, Guite et al (29) found that siblings of children with FAP experience more emotional/behavioural symptoms than peers; Huntley et al (30) examined sleep disturbances and explored psychiatric disorders and family functioning; Ghanizadeh et al (31) explored psychiatric disorders and family functioning; Claar et al (32) considered pain coping profiles; Dufton et al (33) observed a relationship between anxiety and abdominal pain; Wendland et al (34) explored how depression and pain predicted disability; and van Tilburg et al (35) examined the relationship between abuse/neglect and abdominal pain.

Parents and FAP: The majority of studies confirm the findings of earlier work. For example, Ramchandani et al (14) found that increased maternal anxiety was associated with poor outcomes and increased functional gastrointestinal disorders in mothers of patients with FAP, and they subsequently found increased levels of maternal anxiety in these patients (36). Similarly, Campo et al (37) found that mothers of FAP patients were significantly more likely than mothers of control subjects to have a lifetime history of IBS, migraine, anxiety, and depressive and somatoform disorders, and also to experience current anxiety, depressive and somatic symptoms, poorer overall quality of life and greater use of ambulatory health care services. Fathers continue to be largely unstudied in this area of research. It would be preferable for future studies to attempt to include fathers, although it is recognized that this may be difficult.

Other factors studied: Other areas studied include fructose intolerance (38), gastric myoelectrical and motor abnormalities (39), joint hypermobility (40), and knowledge and attitudes among school nurses regarding abdominal pain (41).

\section{Limitations}

The studies on FAP in the past five years present several possible areas for further investigation. However, most are hampered by small patient numbers and other methodological problems, hindering their ability to provide information regarding this condition, and further work is warranted. The literature is in need of well-designed studies to build on preliminary findings through the use of larger samples and prospective studies. The authors have taken such an approach in their own work, which will be discussed below.

\section{EARLIER RELATED WORK BY THE AUTHORS' GROUP} Familial illness patterns

This line of research was initiated by identifying families from the administrative database of a large health maintenance organization (HMO) in which at least one parent had been treated for a diagnosis of IBS, a gastrointestinal disorder characterized by chronic pain and no known physiological etiology (42), and who had at least one child three to 14 years of age (43). A matched control group was selected from the same population. Health care utilization records for all children in the study were obtained from the HMO's automated database and included the frequency, type and diagnosis of all health care visits for the three consecutive years of the study. Children of parents with IBS had significantly more ambulatory visits than control children (mean 12.26 versus 9.81 in controls; $\mathrm{t}=5.94 ; \mathrm{P}=0.0001$ ). This was also true for all health care costs $(\mathrm{t}=3.17 ; \mathrm{P}=0.0001)$, ambulatory visits for gastrointestinal symptoms (abdominal pain, diarrhea, constipation; $\mathrm{t}=$ 5.144; $\mathrm{P}=0.0001)$ and emergency room visits $(\mathrm{t}=2.171 ; \mathrm{P}=0.03)$. Parents with IBS made more health care visits than the control parents for nongastrointestinal complaints, in addition to the difference in visits for IBS. They also incurred substantially higher health care costs. These observations suggest that parents with IBS might be transmitting a general pattern of illness behaviour to their children rather than specifically transmitting gastrointestinal illness behaviour. In a subsequent study (44), in addition to obtaining data from an automated database, interviews were conducted and questionnaires were collected from both parents and children. Importantly, children were interviewed separately from their parents. Similar to the previous study, this study found that children of parents with IBS independently reported more frequent stomachaches $(\mathrm{F}[591]=9.22 ; \mathrm{P}=0.0025)$ and nongastrointestinal symptoms $(\mathrm{F}[562]=21.03 ; \mathrm{P}<0.001)$ than control children. Children of parents with IBS also reported more school absences $(\mathrm{F}[625]=26.53 ; \mathrm{P}<0.0001)$, more physician visits for gastrointestinal symptoms $(\mathrm{F}[602]=8.09 ; \mathrm{P}=0.005)$ and more nongastrointestinal clinic visits $(\mathrm{F}[602]=27.92 ; \mathrm{P}<0.001)$ than control children.

\section{Familial genetics}

To assess the relative contribution of genetic and social learning influences to this intergenerational pattern, concordance rates for IBS in monozygotic (MZ) and dizygotic (DZ) twins were compared with concordance between mothers and their children (45). The concordance for $\mathrm{MZ}$ twins was $17.2 \%$ compared with $8.4 \%$ for DZ twins $\left(\chi^{2}=4.70\right.$; $\mathrm{P}=0.030)$. The probability that a DZ twin with IBS will have a mother with IBS was $15.2 \%$. This was significantly greater $(\mathrm{P}<0.001)$ than the probability that a DZ twin with IBS will have a co-twin with IBS (6.7\%); the probability that an MZ twin with IBS will have a mother with IBS $(17.1 \%)$ was also significantly greater $(\mathrm{P}<0.001)$ than the probability that a DZ twin with IBS will have a co-twin with IBS (6.7\%). Thus, while there does appear to be some genetic contribution to the development of IBS, the authors believe that these data support a stronger social learning contribution to IBS, because mothers share approximately the same number of genes with their children as DZ twins share with one another, yet the proportion of IBS twins who have mothers with IBS is significantly greater than the proportion of DZ twins with IBS whose co-twins have IBS.

\section{Familial traits}

Possible explanations for the relationship between parental and child illness patterns were also explored within this research program by investigating inter- and intrapersonal influences on illness behaviour. Specifically, the relative contributions to medical consultation of the psychological symptoms of the mother and child, the severity of child abdominal pain and the level of family stress were determined (46). In a stepwise regression, only maternal psychological symptoms and perceived pain severity significantly predicted consultation $(\mathrm{P}=0.006$ and $\mathrm{P}<0.001$, respectively). Thus, a principal finding of this study was that a child's visit to the clinic for abdominal pain is best predicted by symptoms of psychological distress in the mother and severity of abdominal pain as reported by the child, rather than psychological distress in the child or family stress.

In a related study regarding social learning process influences of this intergenerational transmission pattern (47), the authors explored whether catastrophic thinking about pain by children with FAP or by their parents is associated with health outcomes in the child. Child catastrophizing predicted child depression, anxiety and functional 
disability. Parents' catastrophizing cognitions about their own pain predicted self-reported protective responses to their children's abdominal pain (responding in ways that encourage illness behaviour).

\section{Familial mechanisms or processes}

Next, the mechanisms by which these parental behaviours or traits were being transmitted from parent to child were considered. Two social learning phenomena, modelling and reinforcement, were plausible suspect mechanisms. An example of modelling, in which children imitate their parents, could occur when parents stay home from work and expect special consideration (eg, help with chores). Children could then become hypervigilant to somatic sensations, report more symptoms and want to stay home from school. Because it is known that this is a group of parents with higher illness behaviours, learning through the observational process of modelling is one plausible explanation for the data revealing higher rates of illness, which are not explained by genetics, among children of parents with IBS.

Another possible mechanism that could contribute to learning is reinforcement, in which behaviours that are rewarded are repeated. In a study by Levy et al (44), reinforcement was explored by administering the Illness Behavior Encouragement Scale (48), later renamed the Adult Response to Child Symptoms scale (49). Among other findings, it was determined that children with higher school absentee levels for gastrointestinal symptoms as reported by their mothers were more likely to have parents who were also more solicitous in response to their child's symptoms $(\mathrm{F}[625]=5.33 ; \mathrm{P}<0.05)$.

In summary, the authors' observational findings have determined the following:

- Children's illness behaviour/reported pain is related to that of their parents, and learning appears to account for much of this phenomenon.

- Child and adult illness behaviour/reported pain is related to environmental response, especially how parents respond.

- The decision to take a child to the clinic because of abdominal pain is best predicted by the child's perceived pain severity and maternal psychological distress.

\section{TREATMENT STUDIES 2007-2011}

How each patient is treated for pain or any medical phenomenon is also influenced by personal history, knowledge base and, again unfortunately, sometimes potential financial gain. Many treatments for FAP were tested in randomized controlled trials for the first time during this period of time. Most included medications and probiotics, yoga or relaxation, and variations on therapy derived from social learning principles.

\section{Medications and probiotics}

Probiotics have begun to be investigated in children, with some positive results (50-52). These findings may hold promise for a group of children.

Medications such as amitriptyline (53), cyproheptadine (54) and tegaserod (55) are all beginning to be explored, but results are very preliminary, may include side effects, and often there is no long-term follow-up, with poor controls or no control groups.

Psychological treatments, yoga and biofeedback

Yoga (56), biofeedback (57) and restoration of vagal tone (58) have all shown some promise, although further research is needed. Hypnotherapy (59-62) has yielded some impressive and long-term results. The findings show promise and merit further study.

To address many of the methodological problems with previous research, the authors designed and conducted a randomized controlled trial in which 200 children with persistent FAP and their parents were randomly assigned to one of two intervention groups: a three-session intervention of cognitive-behavioural treatment targeting parents' responses to their children's pain complaints and children's coping responses; or a three-session educational intervention that controlled for time and attention. Children in the cognitive-behavioural group showed greater baseline to follow-up decreases in pain and gastrointestinal symptom severity than children in the comparison group. Also, parents in the cognitive-behavioural group reported greater decreases in solicitous responses to their children's symptoms compared with parents in the educational intervention group (63).

\section{CONCLUSIONS}

Children with FAP have a lower quality of life, with negative effects that can persist into adulthood. They experience higher rates of psychological distress, and similar disorders tend to run in families. Physiological studies into the etiology of this phenomenon are ongoing, but are presently limited. The main findings of increased hypersensitivity in children are similar to those in adults with FAP, but until recently studies in children were lacking. Child illness behaviour/reported pain appears to be related to how parents respond to children's illness behaviour, with maternal psychological distress being the best predictor of a child presenting at the clinic for abdominal pain.

Based on the authors' work and that of others, it is believed that the best current recommendations for clinicians are as follows:

- For children: Attempt to reduce threat and/or catastrophic thinking and promote relaxation strategies.

- For parents: Attempt to reduce threat and/or catastrophic thinking about their child's pain, and train in alternative ways of responding to illness behaviour that encourage wellness.

- Probiotics represent a potential treatment.

For researchers, the authors suggest that future studies include the following:

- Sample sizes of more than 50 individuals per group.

- Investigation of physiological mechanisms.

- Examination of alternative treatment delivery strategies, such as different personnel (eg, school nurses) and remote technologies (eg, the Internet).

- Comparison conditions that control for time and attention, where treatment fidelity is assessed.

- Long-term follow-up (one year).

- Measurement of the process as well as outcome variables.

CONFLICT OF INTEREST: The authors have no conflicts of interest to declare regarding the content of this article.

\section{REFERENCES}

1. Di Lorenzo C, Colletti RB, Lehmann HP, et al. Chronic abdominal pain in children: A technical report of the American Academy of Pediatrics and the North American Society for Pediatric

Gastroenterology, Hepatology and Nutrition. J Pediatr Gastroenterol Nutr 2005;40:249-61.

2. Apley J, Naish N. Recurrent abdominal pains: A field survey of 1,000 school children. Arch Dis Child 1958;33:165-70.

3. Mechanic D. Sex, illness, illness behavior, and the use of health services. Soc Sci Med Part B: Medical Anthropology 1978;12:207-14.

4. Drossman DA, Li Z, Andruzzi E, et al. U.S. householder survey of functional gastrointestinal disorders. Prevalence, sociodemography, and health impact. Dig Dis Sci 1993;38:1569-80.

5. Chitkara DK, Rawat DJ, Talley NJ. The epidemiology of childhood recurrent abdominal pain in western countries: A systematic review. Am J Gastroenterol 2005;100:1868-75.

6. Saps M, Seshadri R, Sztainberg M, Schaffer G, Marshall BM, Di Lorenzo C. A prospective school-based study of abdominal pain and other common somatic complaints in children. J Pediatr 2009;154:322-6.

7. Oostenbrink R, Jongman H, Landgraf JM, Raat H, Moll HA. Functional abdominal complaints in pre-school children: Parental reports of health-related quality of life. Qual Life Res 2010;19:363-9.

8. Dhroove G, Chogle A, Saps M. A million-dollar work-up for abdominal pain: Is it worth it? J Pediatr Gastroenterol Nutr 2010;51:579-83.

9. Gulewitsch MD, Enck P, Hautzinger M, Schlarb AA. Irritable bowel syndrome symptoms among German students: Prevalence, characteristics, and associations to somatic complaints, sleep, quality of life, and childhood abdominal pain. Eur J Gastroenterol Hepatol 2011;23:311-6. 
10. Chitkara DK, Talley NJ, Schleck C, Zinsmeister AR, Shah ND, Locke GR 3rd. Recollection of childhood abdominal pain in adults with functional gastrointestinal disorders. Scand J Gastroenterol 2009;44:301-7.

11. Dengler-Crish CM, Horst SN, Walker LS. Somatic complaints in childhood functional abdominal pain are associated with functional gastrointestinal disorders in adolescence and adulthood. J Pediatr Gastroenterol Nutr 2011;52:162-5.

12. van Gessel H, Gaszmann J, Kroner-Herwig B. Children in pain: Recurrent back pain, abdominal pain, and headache in children and adolescents in a four-year-period. J Pediatr 2011;158:977-83.e2.

13. Walker LS, Dengler-Crish CM, Rippel S, Bruehl S. Functional abdominal pain in childhood and adolescence increases risk for chronic pain in adulthood. Pain 2010;150:568-72.

14. Ramchandani PG, Fazel M, Stein A, Wiles N, Hotopf M. The impact of recurrent abdominal pain: Predictors of outcome in a large population cohort. Acta Paediatr 2007;96:697-701.

15. Galli F, D'Antuono G, Tarantino S, et al. Headache and recurrent abdominal pain: A controlled study by the means of the Child Behaviour Checklist (CBCL). Cephalalgia 2007;27:211-9.

16. Teitelbaum JE, Sinha P, Micale M, Yeung S, Jaeger J. Obesity is related to multiple functional abdominal diseases. J Pediatr 2009;154:444-6.

17. Malaty HM, Abudayyeh S, Fraley K, Graham DY, Gilger MA, Hollier DR. Recurrent abdominal pain in school children: Effect of obesity and diet. Acta Paediatr 2007;96:572-6.

18. Bonilla S, Saps M, Wang D. Obesity predicts persistence of pain in children with functional gastrointestinal disorders. Int J Obes 2011;35:517-21.

19. Shulman RJ, Eakin MN, Czyzewski DI, Jarrett M, Ou CN. Increased gastrointestinal permeability and gut inflammation in children with functional abdominal pain and irritable bowel syndrome. J Pediatr 2008;153:646-50.

20. Saps M, Pensabene L, Di Martino L, et al. Post-infectious functional gastrointestinal disorders in children. J Pediatr 2008;152:812-6.e1.

21. Schurman JV, Singh M, Singh V, Neilan N, Friesen CA. Symptoms and subtypes in pediatric functional dyspepsia: Relation to mucosal inflammation and psychological functioning. J Pediatr Gastroenterol Nutr 2010;51:298-303.

22. Saps M, Lu P, Bonilla S. Cow's-milk allergy is a risk factor for the development of FGIDs in children. J Pediatr Gastroenterol Nutr 2011;52:166-9.

23. Halac U, Noble A, Faure C. Rectal sensory threshold for pain is a diagnostic marker of irritable bowel syndrome and functional abdominal pain in children. J Pediatr 2010;156:60-5.e1.

24. Bakker MJ, Boer F, Benninga MA, Koelman JH, Tijssen MA. Increased auditory startle reflex in children with functional abdominal pain. J Pediatr 2010;156:285-91.

25. Dengler-Crish CM, Bruehl S, Walker LS. Increased wind-up to heat pain in women with a childhood history of functional abdominal pain. Pain 2011;152:802-8.

26. Bruehl S, Dengler-Crish CM, Smith CA, Walker LS. Hypoalgesia related to elevated resting blood pressure is absent in adolescents and young adults with a history of functional abdominal pain. Pain 2010;149:57-63.

27. Friesen CA, Lin Z, Schurman JV, Andre L, McCallum RW. The effect of a meal and water loading on heart rate variability in children with functional dyspepsia. Dig Dis Sci 2010;55:2283-7.

28. Dufton LM, Dunn MJ, Slosky LS, Compas BE. Self-reported and laboratory-based responses to stress in children with recurrent pain and anxiety. J Pediatr Psychol 2011;36:95-105.

29. Guite JW, Lobato DJ, Shalon L, Plante W, Kao BT. Pain, disability, and symptoms among siblings of children with functional abdominal pain. J Dev Behav Pediatr 2007;28:2-8.

30. Huntley ED, Campo JV, Dahl RE, Lewin DS. Sleep characteristics of youth with Functional Abdominal Pain and a healthy comparison group. J Pediatr Psychol 2007;32:938-49.

31. Ghanizadeh A, Moaiedy F, Imanieh MH, et al. Psychiatric disorders and family functioning in children and adolescents with functional abdominal pain syndrome. J Gastroenterol Hepatol 2008;23(7 Pt1):1132-6.

32. Claar RL, Baber KF, Simons LE, Logan DE, Walker LS. Pain coping profiles in adolescents with chronic pain. Pain 2008;140:368-75.

33. Dufton LM, Dunn MJ, Compas BE. Anxiety and somatic complaints in children with recurrent abdominal pain and anxiety disorders. J Pediatr Psychol 2009;34:176-86.
34. Wendland M, Jackson Y, Stokes LD. Functional disability in paediatric patients with recurrent abdominal pain. Child Care Health Dev 2010;36:516-23.

35. van Tilburg MAL, Runyan DK, Zolotor AJ, et al. Unexplained gastrointestinal symptoms after abuse in a prospective study of children at risk for abuse and neglect. Ann Fam Med 2010;8:134-40.

36. Ramchandani PG, Murray L, Romano G, Vlachos H, Stein A. An investigation of health anxiety in families where children have recurrent abdominal pain. J Pediatr Psychol 2011;36:409-19.

37. Campo JV, Bridge J, Lucas A, et al. Physical and emotional health of mothers of youth with functional abdominal pain. Arch Pediatr Adolesc Med 2007;161:131-7.

38. Gomara RE, Halata MS, Newman LJ, et al. Fructose intolerance in children presenting with abdominal pain. J Pediatr Gastroenterol Nutr 2008;47:303-8.

39. Devanarayana NM, de Silva DG, de Silva HJ. Gastric myoelectrical and motor abnormalities in children and adolescents with functional recurrent abdominal pain. J Gastroenterol Hepatol 2008;23:1672-7.

40. Zarate N, Farmer AD, Grahame R, et al. Unexplained gastrointestinal symptoms and joint hypermobility: Is connective tissue the missing link? Neurogastroenterol Motil 2010;22:252-61.e78.

41. Youssef NN, Murphy TG, Schuckalo S, Intile C, Rosh J. School nurse knowledge and perceptions of recurrent abdominal pain: Opportunity for therapeutic alliance? Clin Pediatr (Phila) 2007;46:340-4.

42. Drossman DA, Corazziari E, Delvaux M, et al, eds. Rome III: The functional gastrointestinal disorders. McLean, Virginia: Degnon Associates, 2006.

43. Levy RL, Whitehead WE, Von Korff MR, Feld AD. Intergenerational transmission of gastrointestinal illness behavior. Am J Gastroenterol 2000;95:451-6.

44. Levy RL, Whitehead WE, Walker LS, et al. Increased somatic complaints and health-care utilization in children: Effects of parent IBS status and parent response to gastrointestinal symptoms. Am J Gastroenterol 2004;99:2442-51.

45. Levy RL, Jones KR, Whitehead WE, Feld SI, Talley NJ, Corey LA. Irritable bowel syndrome in twins: Heredity and social learning both contribute to etiology. Gastroenterology 2001;121:799-804.

46. Levy RL, Langer SL, Walker LS, Feld LD, Whitehead WE. Relationship between the decision to take a child to the clinic for abdominal pain and maternal psychological distress. Arch Pediatr Adolesc Med 2006;160:961-5.

47. Langer SL, Romano JM, Levy RL, Walker LS, Whitehead WE. Catastrophizing and parental response to child symptom complaints. Child Health Care 2009;38:169-84.

48. Walker LS, Zeman JL. Parental response to child illness behavior. J Pediatr Psychol 1992;17:49-71.

49. Walker LS, Claar RL, Garber J. Social consequences of children's pain: When do they encourage symptom maintenance? J Pediatr Psychol 2002;27:689-98.

50. Martens U, Enck P, Zieseniss E. Probiotic treatment of irritable bowel syndrome in children. Ger Med Sci 2010;8:Doc07.

51. Francavilla R, Miniello V, Magistà AM, et al. A randomized controlled trial of lactobacillus GG in children with functional abdominal pain. Pediatrics 2010;126:e1445-52.

52. Gawronska A, Dziechciarz P, Horvath A, Szajewska H. A randomized double-blind placebo-controlled trial of Lactobacillus GG for abdominal pain disorders in children. Aliment Pharmacol Ther 2007;25:177-84.

53. Saps M, Youssef N, Miranda A, et al. Multicenter, randomized, placebo-controlled trial of amitriptyline in children with functional gastrointestinal disorders. Gastroenterology 2009;137:1261-9.

54. Sadeghian M, Farahmand F, Fallahi GH, Abbasi A. Cyproheptadine for the treatment of functional abdominal pain in childhood: A double-blinded randomized placebo-controlled trial. Minerva Pediatr 2008;60:1367-74.

55. Liem O, Mousa HM, Benninga MA, Di Lorenzo C. Tegaserod use in children: A single-center experience. J Pediatr Gastroenterol Nutr 2008;46:54-8.

56. Evans S, Cousins L, Tsao JC, Sternlieb B, Zeltzer LK. Protocol for a randomized controlled study of Iyengar yoga for youth with irritable bowel syndrome. Trials 2011;12:15.

57. Schurman JV, Wu YP, Grayson P, Friesen CA. A pilot study to assess the efficacy of biofeedback-assisted relaxation training as an adjunct treatment for pediatric functional dyspepsia associated with duodenal eosinophilia. J Pediatr Psychol 2010;35:837-47. 
58. Sowder E, Gevirtz R, Shapiro W, Ebert C. Restoration of vagal tone: A possible mechanism for functional abdominal pain. Appl Psychophysiol Biofeedback 2010;35:199-206.

59. Vlieger AM, Menko-Frankenhuis C, Wolfkamp SC, Tromp E, Benninga MA. Hypnotherapy for children with functional abdominal pain or irritable bowel syndrome: A randomized controlled trial. Gastroenterology 2007;133:1430-6.

60. Vlieger AM, van den Berg MM, Menko-Frankenhuis C, Bongers ME, Tromp E, Benninga MA. No change in rectal sensitivity after gutdirected hypnotherapy in children with functional abdominal pain or irritable bowel syndrome. Am J Gastroenterol 2010;105:213-8.
61. Vlieger AM, Rutten JM, Govers AM, Frankenhuis C, Benninga MA. Long-term follow-up of gut-directed hypnotherapy vs. standard care in children with functional abdominal pain or irritable bowel syndrome. Am J Gastroenterol 2012;107:627-31.

62. van Tilburg MAL, Chitkara DK, Palsson OS, et al. Audio-recorded guided imagery treatment reduces functional abdominal pain in children: A pilot study. Pediatrics 2009;124:e890-7.

63. Levy RL, Langer SL, Walker LS, et al. Cognitive-behavioral therapy for children with functional abdominal pain and their parents decreases pain and other symptoms. Am J Gastroenterol 2010;105:946-56. 


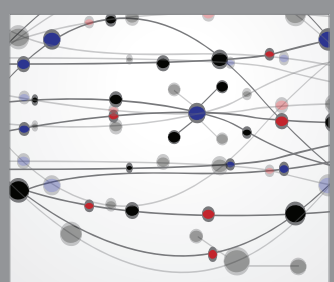

The Scientific World Journal
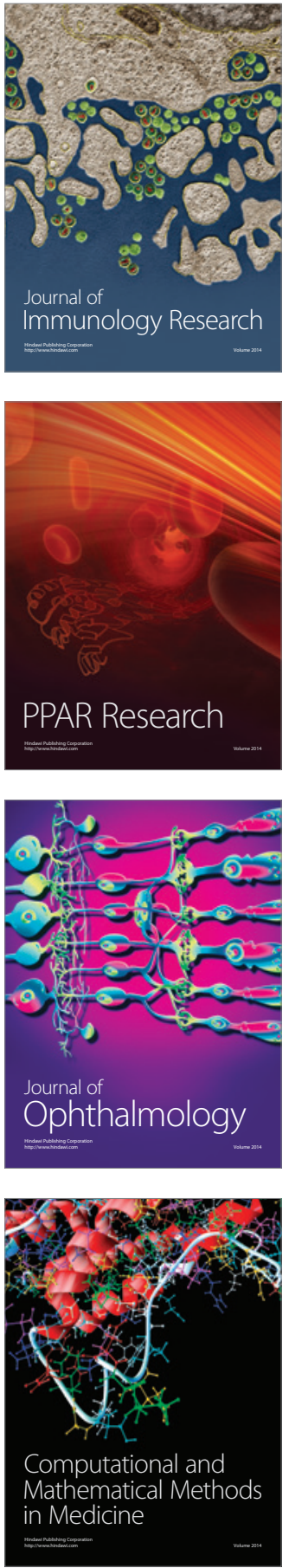

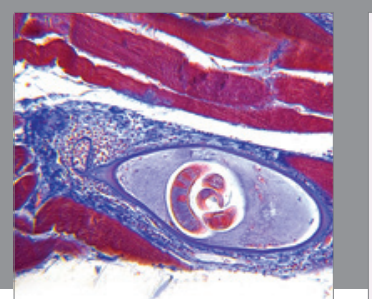

Gastroenterology Research and Practice

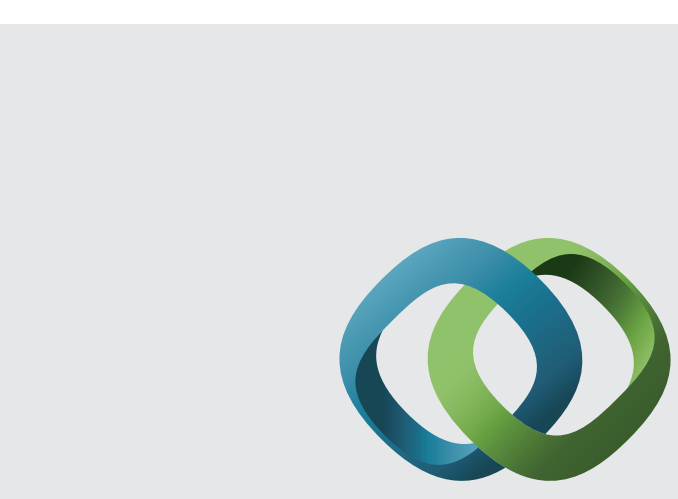

\section{Hindawi}

Submit your manuscripts at

http://www.hindawi.com
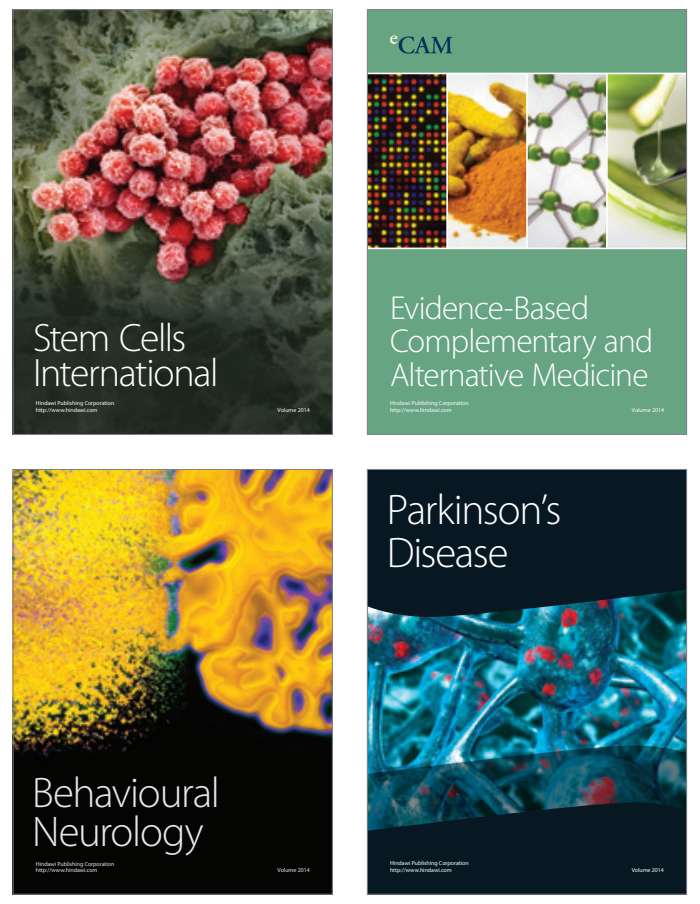
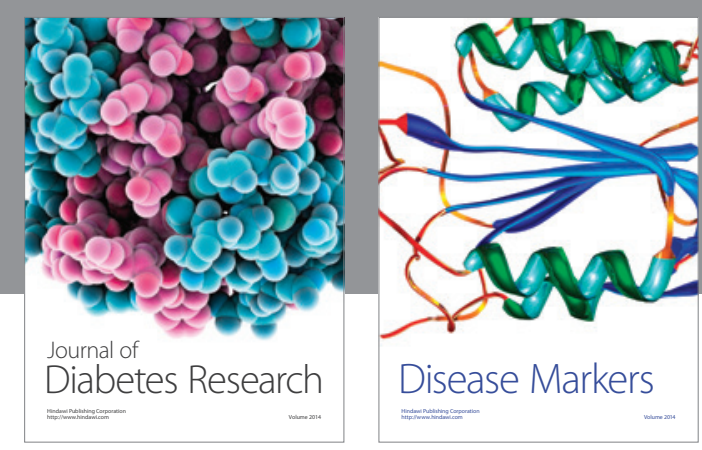

Disease Markers
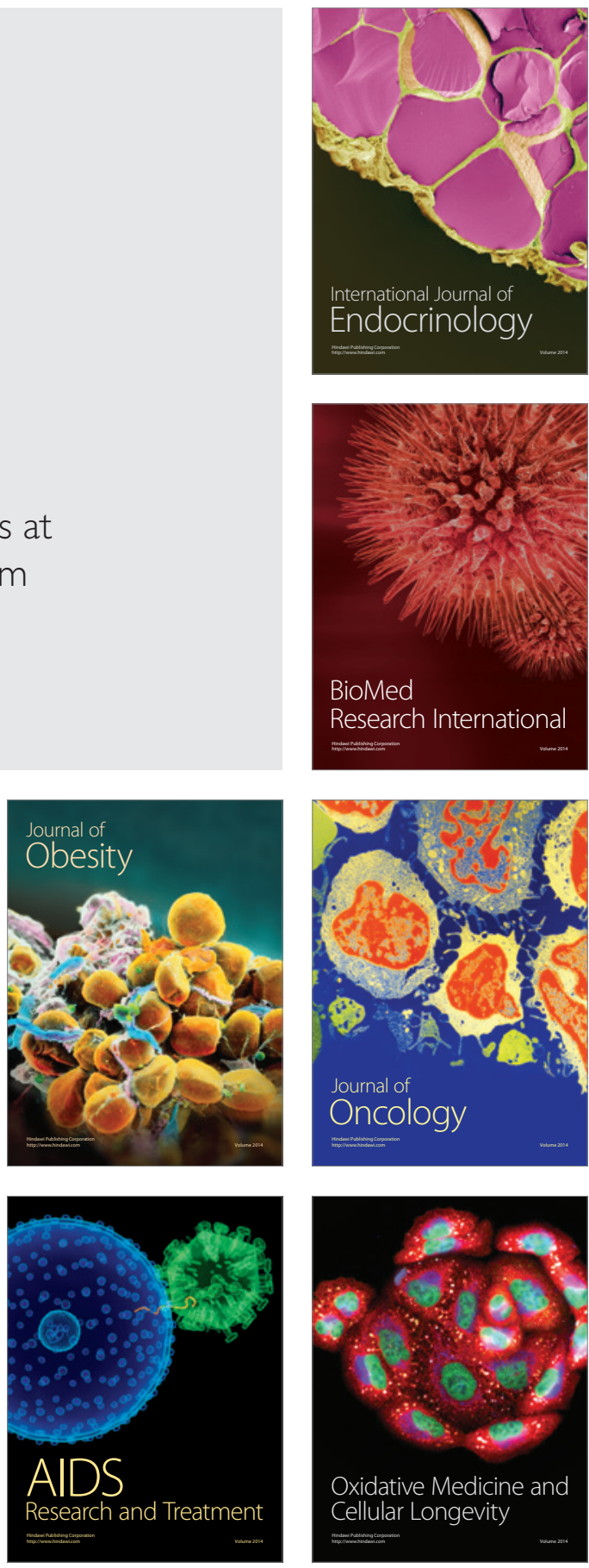